\title{
Switching from the pocket-creation method to double clip and rubber-band traction in colonic endoscopic submucosal dissection
}

Endoscopic submucosal dissection (ESD) has become the standard treatment for large superficial colorectal neoplasms. The pocket-creation method developed in Japan is safe and has a high en bloc resection rate [1]. However, the method cannot be completed if the fibrosis is severe or the approach to the lesion is unstable [2]. These technical difficulties necessitate a switch in strategy. We demonstrate the effective treatment of colonic neoplasms by switching the ESD strategy from the pocket-creation method to the double clip and rubber-band traction method ( $\boldsymbol{F i g . 1} \mathbf{a}-\mathbf{d}$ ), now rapidly accepted in the Western countries $[3,4]$ ( Video 1 ).

The first case was the recurrence of a sigmoid adenocarcinoma following a previous endoscopic mucosal resection. The elevated lesion $(10 \times 15 \mathrm{~mm})$ was located within the scar ( Fig.2a-b). Although we initially attempted creating a pocket using a small-caliber-tip transparent hood, the submucosal space was narrowed by severe fibrosis ( $\mathbf{F i g . 2} \mathbf{c}$ ). In light of the potential technical difficulty, the ESD strategy was changed to the double clip and rubber-band traction method. After complete mucosal incision, we caught the edge of the lesion with the first recapture clip, which was grasping a rubber band. The second clip catching the rubber band was then placed on the opposite wall. This traction method is flexible because the rubber band can be stretched or loosened according to the endoscopic air supply. This method allowed us to clearly expose the submucosal layer ( $\triangleright$ Fig. 2 d) and perform en bloc resection.

The second case was a cecal cancer. The elevated lesion $(22 \times 24 \mathrm{~mm})$ was located

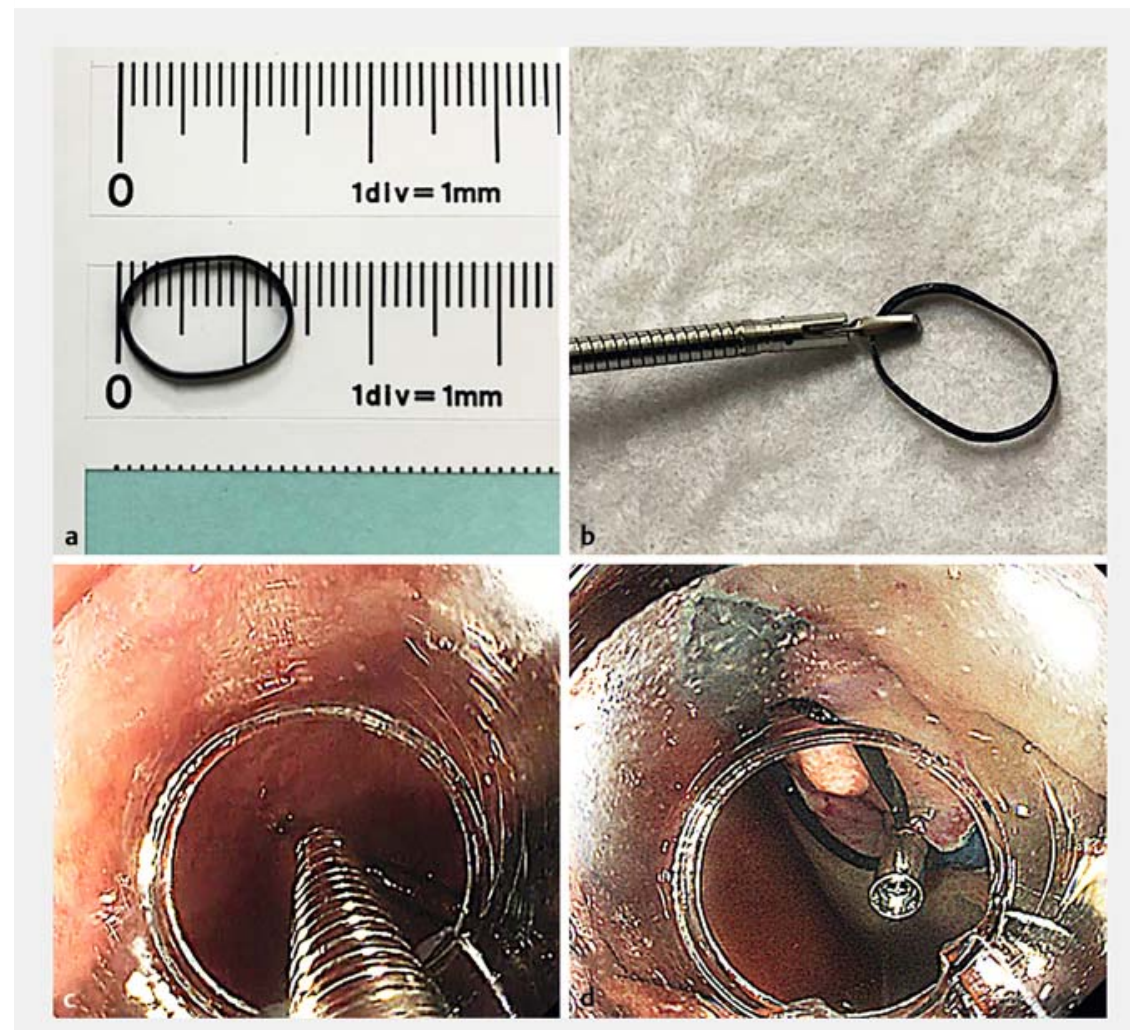

Fig. 1 Double clip and rubber-band traction. a The image of the rubber band (14 mm). b The image of grasping the rubber band with endoscopic forceps. c The first clip, which was grasping a rubber band, was placed at the edge of the lesion. $\mathbf{d}$ The second clip catching the rubber band was placed on the opposite wall of the colon.

under the ileocecal valve ( $\mathbf{F i g . 3} \mathbf{a}-\mathbf{b}$ ). Here, an unstable approach to the lesion (respiratory fluctuation and intestinal peristalsis) prompted us to change the ESD strategy ( $\vee$ Fig. $\mathbf{3 c}-\mathbf{d}$ ).

ESD with the double clip and rubberband traction method is usually planned but without the use of a small-caliber transparent hood ( $\mathbf{F i g . 4 )}$. We illustrate the feasibility and effectiveness of switching the ESD strategy from the pocket-creation to the double clip and rubber-band traction method.

Endoscopy_UCTN_Code_TTT_1AQ_2AD

Competing interests

The authors declare that they have no conflict of interest. 


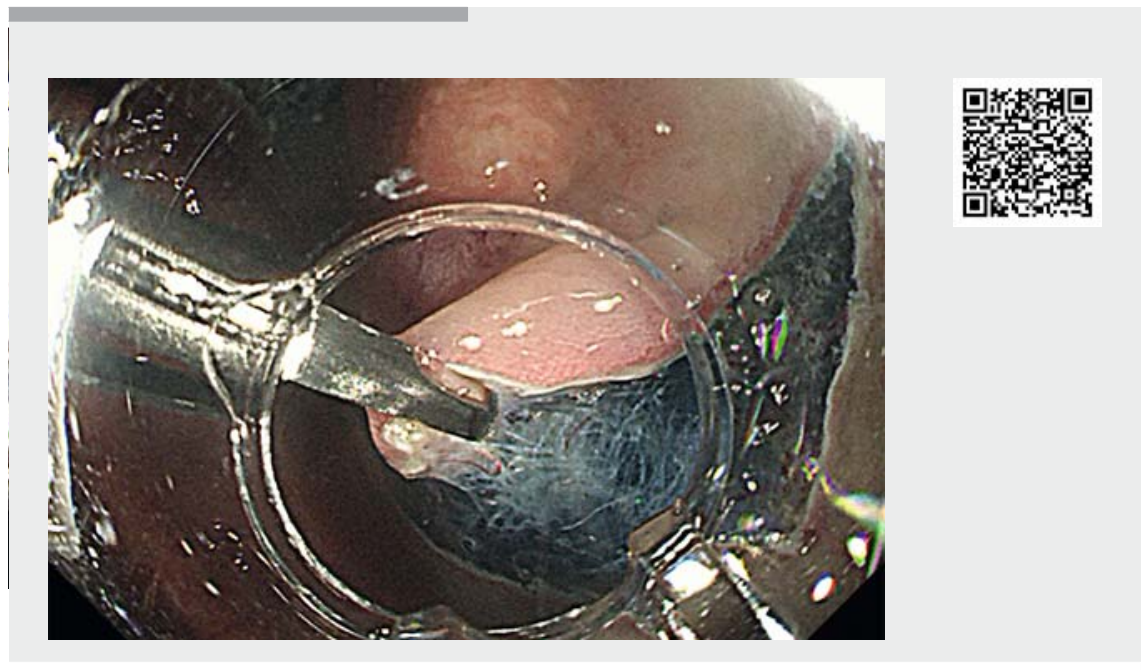

$\checkmark$ Video 1 The two colonic neoplasms were effectively treated by switching from the pocket-creation method to the double clip and rubber-band traction method in endoscopic submucosal dissection.
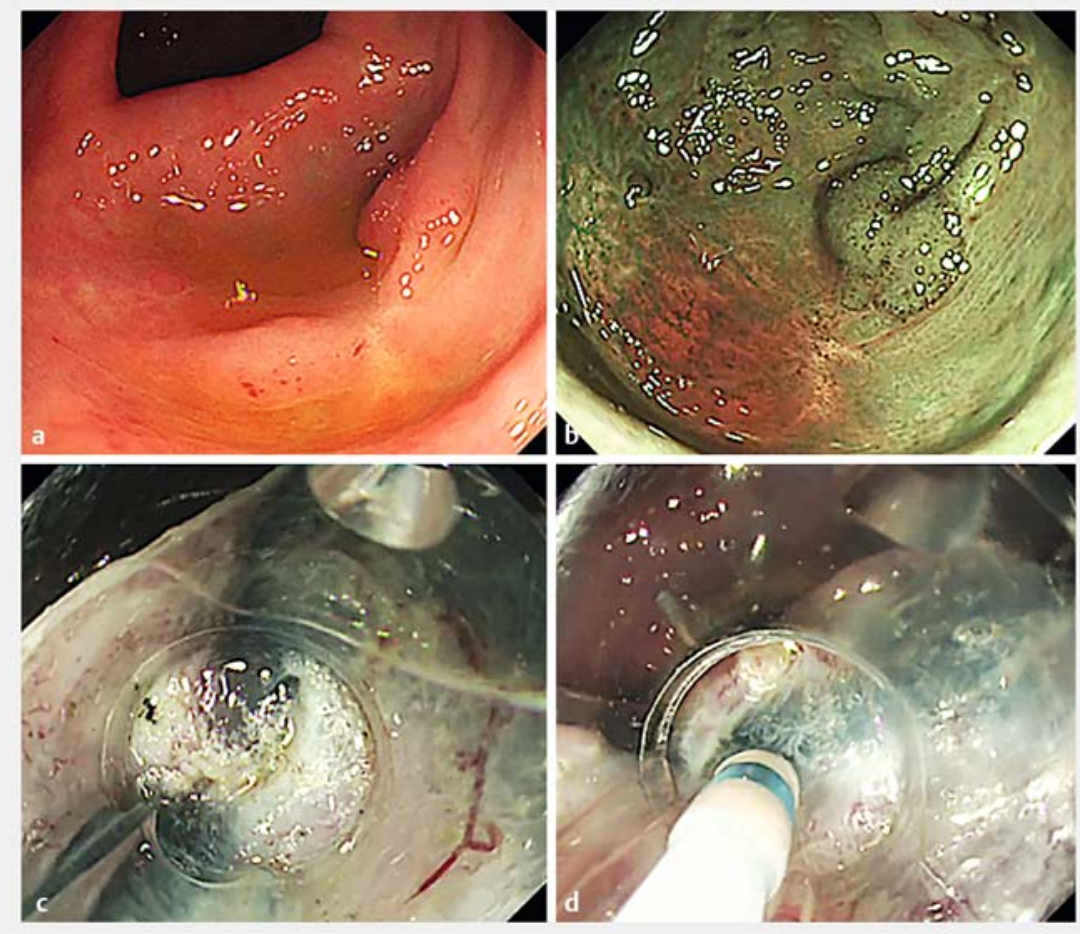

- Fig. 2 Case 1, recurrence of a sigmoid adenocarcinoma. a An elevated lesion, $15 \mathrm{~mm}$ in diameter, located within the scar. $\mathbf{b}$ Endoscopic image with a narrow banding image. $\mathbf{c}$ The submucosal layer was too narrow owing to severe fibrosis. $\mathbf{d}$ The submucosal layer was exposed after circumferential incision and double clip and rubber-band traction.
The authors

Yasutoshi Shiratori, Takaaki Yoshimoto, Takashi lkeya

Division of Gastroenterology, St. Luke's

International Hospital, Tokyo, Japan

Corresponding author

\section{Yasutoshi Shiratori, MD}

St. Luke's International Hospital, Division of Gastroenterology, 9-1 Akashi-cho Chuo-ku, Tokyo 104-8340, Japan

Fax: +81-3-3541-5151

shiraya@luke.ac.jp

\section{References}

[1] Harada H, Nakahara R, Murakami D et al. Saline-pocket endoscopic submucosal dissection for superficial colorectal neoplasms: a randomized controlled trial (with video). Gastrointest Endosc 2019; 90: 278-287

[2] Yamashina T, Nemoto D, Hayashi Y et al. A prospective randomized trial comparing the pocket-creation method and conventional method of colorectal endoscopic submucosal dissection. Gastrointest Endosc 2020. doi:10.1016/j.gie.2020.02.034

[3] Faller J, Jacques ], Oung B et al. Endoscopic submucosal dissection with double clip and rubber band traction for residual or locally recurrent colonic lesions after previous endoscopic mucosal resection. Endoscopy 2020; 52: 383-388

[4] Oung B, Rivory J, Chabrun E et al. ESD with double clips and rubber band traction of neoplastic lesions developed in the appendiceal orifice is effective and safe. Endosc Int Open 2020; 8: 388-395 

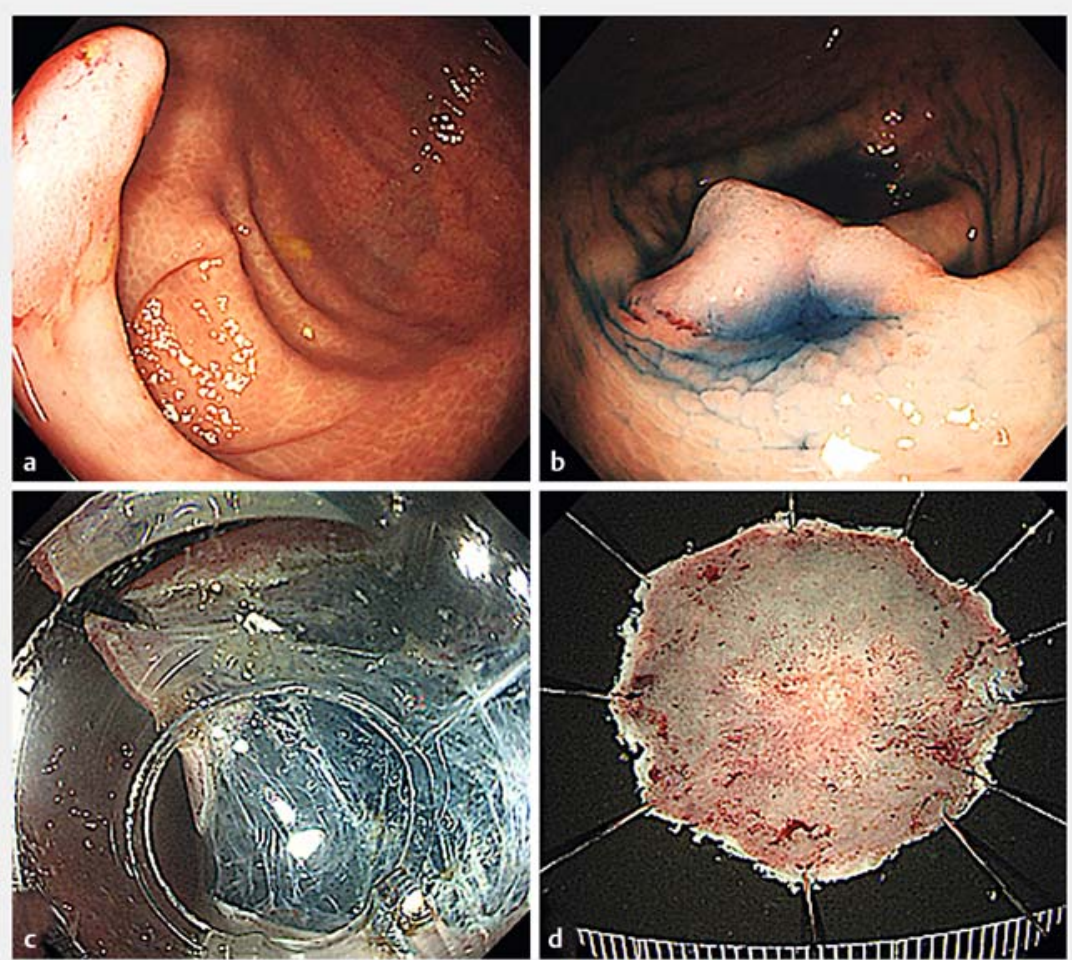

Fig. 3 Case 2, cecal cancer. a An elevated lesion, $24 \mathrm{~mm}$ in diameter, located between the ileocecal valve and the appendiceal orifice. $\mathbf{b}$ Endoscopic image with indigo carmine dye depicting a clear demarcation line. c Double clips and rubber-band traction allowed us to clearly expose the submucosal layer of the lesion. $\mathbf{d}$ Macroscopic image of the endoscopically resected specimen. En bloc resection was achieved.

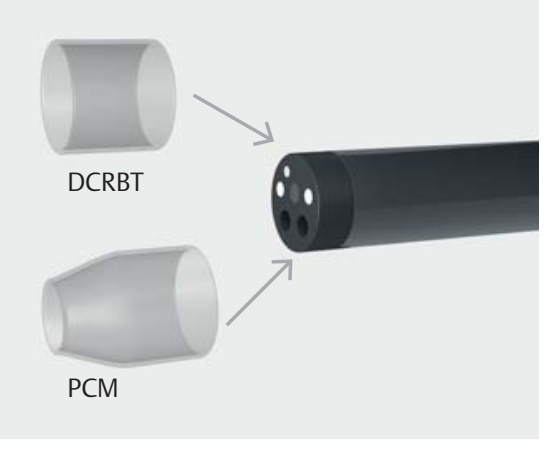

- Fig. 4 A comparison of the endoscopic hood. Usually, the conventional hood is used in the double clip and rubber-band traction method (DCRBT), whereas the small-caliber transparent hood is used in the pocket-creation method (PCM).

\section{Bibliography}

Endoscopy 2021; 53: E166-E168

DOI 10.1055/a-1226-6238

ISSN 0013-726X

published online 20.8.2020

(c) 2020. Thieme. All rights reserved.

Georg Thieme Verlag KG, Rüdigerstraße 14, 70469 Stuttgart, Germany

\section{ENDOSCOPY E-VIDEOS \\ https://eref.thieme.de/e-videos}

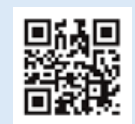

Endoscopy E-Videos is a free access online section, reporting on interesting cases and new

techniques in gastroenterological endoscopy. All papers include a high quality video and all contributions are freely accessible online.

This section has its own submission website at

https://mc.manuscriptcentral.com/e-videos 